Article

\title{
Chimeric Vaccines Designed by Immunoinformatics-Activated Polyfunctional and Memory $T$ cells that Trigger Protection against Experimental Visceral Leishmaniasis
}

\author{
Rory Cristiane Fortes De Brito ${ }^{1,+} \oplus^{\circ}$, Jeronimo Conceição Ruiz ${ }^{2,3,+} \oplus^{\infty}$, \\ Jamille Mirelle de Oliveira Cardoso ${ }^{1}$, Thais Lopes Valentim Di Paschoale Ostolin ${ }^{1}$, \\ Levi Eduardo Soares Reis ${ }^{1}$, Fernando Augusto Siqueira Mathias ${ }^{1}$, \\ Rodrigo Dian de Oliveira Aguiar-Soares ${ }^{1}$, Bruno Mendes Roatt ${ }^{1,4}{ }^{\mathbb{D}}$, Rodrigo Corrêa-Oliveira ${ }^{5}$, \\ Daniela de Melo Resende ${ }^{2,3}$ and Alexandre Barbosa Reis 1,4,* \\ 1 Laboratório de Imunopatologia, Núcleo de Pesquisas em Ciências Biológicas/NUPEB, Universidade Federal \\ de Ouro Preto, Ouro Preto 35400-000, Brazil; rorybrito@gmail.com (R.C.F.D.B.); \\ ja_mirelle@yahoo.com.br (J.M.d.O.C.); thais.ostolin@gmail.com (T.L.V.D.P.O.); \\ levieduardo@yahoo.com.br (L.E.S.R.); fa_mathias@yahoo.com.br (F.A.S.M.); \\ rodrigodian@gmail.com (R.D.d.O.A.-S.); roatt@ufop.edu.br (B.M.R.) \\ 2 Grupo Informática de Biossistemas e Genômica, Instituto René Rachou, Fiocruz Minas, \\ Belo Horizonte 30190-002, Brazil; jeronimo.ruiz@fiocruz.br (J.C.R.); \\ dani.melo.resende@gmail.com (D.d.M.R.) \\ 3 Programa de Pós-graduação em Biologia Computacional e Sistemas, Instituto Oswaldo Cruz, Fiocruz, \\ Rio de Janeiro 21040-360, Brazil \\ 4 Instituto Nacional de Ciência e Tecnologia em Doenças Tropicais (INCT-DT), Salvador 40110-160, Brazil \\ 5 Laboratório de Imunologia Celular e Molecular, Instituto René Rachou, Fiocruz Minas, \\ Belo Horizonte 30190-002, Brazil; rodrigo.correa@fiocruz.br \\ * Correspondence: alexreis@ufop.edu.br; Tel.: +55-31-3559-1694 \\ + These authors contributed equally to this study.
}

Received: 7 March 2020; Accepted: 27 March 2020; Published: 27 May 2020

check for updates

\begin{abstract}
Many vaccine candidates against visceral leishmaniasis (VL) have been proposed; however, to date, none of them have been efficacious for the human or canine disease. On this basis, the design of leishmaniasis vaccines has been constantly changing, and the use of approaches to select specific epitopes seems to be crucial in this scenario. The ability to predict $\mathrm{T}$ cell-specific epitopes makes immunoinformatics an even more necessary approach, as in VL an efficient immune response against the parasite is triggered by $\mathrm{T}$ lymphocytes in response to Leishmania spp. immunogenic antigens. Moreover, the success of vaccines depends on the capacity to generate long-lasting memory and polyfunctional cells that are able to eliminate the parasite. In this sense, our study used a combination of different approaches to develop potential chimera candidate vaccines against VL. The first point was to identify the most immunogenic epitopes of Leishmania infantum proteins and construct chimeras composed of Major histocompatibility complex (MHC) class I and II epitopes. For this, we used immunoinformatics features. Following this, we validated these chimeras in a murine model in a thorough memory study and multifunctionality of $\mathrm{T}$ cells that contribute to a better elucidation of the immunological protective mechanisms of polyepitope vaccines (chimera A and B) using multicolor flow cytometry. Our results showed that in silico-designed chimeras can elicit polyfunctional T cells producing $\mathrm{T}$ helper (Th)1 cytokines, a strong immune response against Leishmania antigen, and the generation of central and effector memory $T$ cells in the spleen cells of vaccinated animals that was able to reduce the parasite burden in this organ. These findings contribute two potential candidate vaccines against VL that can be used in further studies, and help in this complex field of vaccine development against this challenging parasite.
\end{abstract}


Keywords: reverse vaccinology; immunoinformatics; chimera vaccine; Leishmania infantum; polyfunctional T cells; memory $\mathrm{T}$ cells; rational design of vaccines

\section{Introduction}

During the last decades, the way in which the immune system works and the protective mechanisms related to vaccination for complex parasites has been extensively interpreted, and the central dogma of vaccination has been mounted [1]. Some studies support the idea that an antigen is capable of inducing long-lasting immunological memory and protective immunity against re-challenge with the same pathogen. Although this concept has been successful in generating potent vaccines for many diseases, leishmaniasis caused by the protozoan parasite Leishmania remains a threatening exception. Thus, the design of leishmaniasis vaccines has been constantly changing, and the use of polyepitope vaccines seems to gain prominent space in this scenario. In one of the pioneering studies of visceral leishmaniasis (VL) polyepitope vaccines, a DNA vaccine containing Leishmania donovani GP63 protein T cell epitopes was proposed. The authors evaluated the immunogenicity of the vaccine in immunized and challenged $B A L B / c$ mice showing increased production of Interferon gama (IFN- $\gamma$ ) and Interleukin (IL)-2 in splenocytes of vaccinated animals. In addition, this vaccine reduced parasite load in the spleen and liver of challenged mice [2]. In light of this, seeking to expand the antigenic repertoire of vaccines, the authors of [3] constructed a multiepitope DNA vaccine that encoded four protein-fused peptides, lipophosphoglycan (LPG)-3, Leishmania major stress inducible protein (LmSTI)-1, cysteine peptidase B (CPB), and cysteine peptidase C (CPC). They evaluated the cytotoxic activity of lymphocytes and IFN- $\gamma$ production in transgenic mouse (holding human MHC alleles, Human leukocyte antigen (HLA)-DRB1 * 0101/HLA-A * 0201), and the results revealed increased cytotoxic pleaseactivity and IFN- $\gamma$ production after immunization [3]. Along the same line of studies, the authors of [4] constructed DNA vaccines based on peptides selected from L. donovani antigens (CPA, CPB, Kinetoplastid membrane protein (KMP)11, Thiol specific-antioxidant protein (TSA), and Elongation factor 1 (P74) that showed a significant reduction of parasite burden in the spleen after immunization using a unique preparation of these antigens as DNA vaccine when the mice were challenge with $L$. donovani promastigotes [4].

The basic assumption that introduction of an antigen into a host will generate protective immunity against the pathogen appears to be invalid. Thus, there are possible reasons for the failures and the possible approaches that may bring success to generation of Leishmania vaccine. First, the traffic of $\mathrm{T}$ cells between lymph nodes and the microenvironment on the site of infection is essential for activation and maturation of the right cells $[1,5]$. Besides this, the major challenge faced by the immunologists is how to identify antigens capable of generating long-lasting immunological memory. Therefore, several approaches to the evaluation of immunological memory have been developed using multicolor flow cytometry, which aims to identify and evaluate effector and memory T lymphocyte subpopulations to validate different vaccine candidates [6]. The ability to predict $\mathrm{T}$ cell-specific epitopes makes immunoinformatics an even more necessary approach, as in VL an efficient immune response against specific epitopes of the parasite is triggered by $\mathrm{T}$ lymphocytes in response to some Leishmania spp. [7-9]. Thus, some research groups have been proposing vaccine candidates on the basis of specific class I and II MHC-binding epitopes mapped to known proteins $[3,4,10]$.

Therefore, the development of polyepitope vaccines is a promising field that has been studied in recent years. In this sense, our study used a combination of different approaches to develop candidate vaccines against VL. The first point was to identify the best tools to map immunogenic epitopes and construct chimeras composed of MHC class I and II epitopes. For this, we used immunoinformatics features described by [9]. Afterwards, we validated these chimeras in BALB/c mice in a thorough memory study and multifunctionality of $\mathrm{T}$ cells that contributes to a better elucidation of the immunological protective mechanisms of chimeras (A and B) constituted of polyepitope vaccines. 


\section{Materials and Methods}

\subsection{Ethical Statement}

The study was performed according to the recommendation of the National Institute of Health, USA. The protocol number 2015/03 was approved by the Ethical Committee for the Use of Experimental Animals (CEUA) of the Universidade Federal de Ouro Preto, Ouro Preto, MG, Brazil. All the experiments were performed to minimize animal suffering.

\subsection{Epitope Mapping and Chimeric Proteins Design}

The chimeric proteins used in this study were designed on the basis of epitopes mapped along Leishmania infantum proteins already described in the literature as vaccine candidates (Table 1). For epitope mapping, an integrative immunoinformatics approach described by $[9,11]$ was used. The epitopes for $\mathrm{T}$ cells were selected on the basis of the highest scores provided by the predictive algorithms. We used a combination of NetCTL and NetMHC to predict MHC class I epitopes and NetMHCII for MHC class II epitopes, thus promiscuous epitopes were selected on the basis of their affinity towards human and mouse MHC alleles that are available for those algorithms. The algorithm NetCTL version 1.2 makes predictions of peptide-MHC class I binding and proteasomal $C$ terminal cleavage, both using artificial neural networks, and transporter associated with antigen processing (TAP) transport efficiency using weight matrix. The tree predictions are then integrated [12]. The thresholds used were 0.15 for the weight on $C$ terminal cleavage, 0.05 for weight on TAP transport efficiency, and 1.0 for epitope identification. NetMHC version 3.0. predicts binding of peptides to different HLA alleles using artificial neural networks and weight matrices, and the prediction is based on $\mathrm{IC}_{50}$ values where strong binder epitopes have an $\mathrm{IC}_{50}$ below $50 \mathrm{nM}$, and weak binder epitopes have an $\mathrm{IC}_{50}$ value below $500 \mathrm{nM}$ [13]. NetMHCII version 1.0 was used, which predicts binding of peptides to 14 different HLA-DR alleles using position specific weight matrices (PSSM) [14]. The thresholds are based on $\mathrm{IC}_{50}-50 \mathrm{nM}$ for strong binder epitopes, and $500 \mathrm{nM}$ for weak binder threshold score.

To compose the chimeric vaccines, these epitopes were repeated in tandem to enhance the immune response after immunization. Chimeric protein A has epitopes from histone protein (H2A), acid ribosomal protein P2 (LiP2a), acid ribosomal protein P0 (LiP0), Leishmania homologue of activated $C$ kinase (LACK), and cysteine peptidase C (CPC). Chimeric protein B is composed of epitopes of cysteine peptidase proteins A and B (CPA and CPB), surface antigenic protein (PSA-50S), and specific amastigote protein A2 (A2). The linker GPGPG amino acid sequence was used to link the epitopes and increase protein stability and processing [15] (Figure S1).

\subsection{Prediction of Epitope Conservancy among Leishmania Species}

The proteome of L. donovani (BPK282A1 strain), Leishmania major (MHOM/IL/81/Friedlin strain), and Leishmania braziliensis (MHOM/BR/1966/M2903 strain) were retrieved from The Kinetoplastid Genomics Resource (TritrypDB). The proteome of Leishmania amazonensis (MHOM/BR/71973/M2269 strain) was retrieved from [16]. To evaluate the conservancy of the selected epitopes among these Leishmania species, the Immune epitope database (IEDB) epitope conservancy tool (http://tools. immuneepitope.org/tools/conservancy/) was used.

\subsection{Prediction of Antigenicity, Allergenicity, and Physicochemical Properties of the Two Chimeras}

To predict the antigenicity of the two constructs (chimeras A and B), ANTIGENpro was used. This algorithm is based on sequences, pathogen-independent prediction method, and an alignment-free prediction method. For the allergenicity prediction, we used AlgPred, which uses a combination of predictive algorithms as described by [17]. The server uses several algorithms (SVMc + MAST + IgEepitope + ARPs BLAST) to check allergenicity of a query sequence, the prediction of allergens is based on similarity of known epitope with any region of a given protein. The server results are reliable and have $85 \%$ precision at -0.4 threshold. 
To define the physical and chemical parameters associated with the constructs, ProtParam web server (from EXPASY) was used to define various physicochemical properties. Parameters as molecular weight $(\mathrm{kDa})$, theoretical isoelectric point $(\mathrm{pI})$, estimated half-life, and grand average of hydropathy were assessed.

\subsection{Tertiary Structure Prediction and Refinement of the Models}

The 3D structures of predicted chimera constructs were assessed by utilizing RaptorX [18], a web server for structure prediction. To improve the quality of the templates, a refinement of the tertiary structures was performed using GalaxyRefine web server [19]. The validation of refined models was carried out using ProSA [20], a web server. This server can predict the quality of the model which is indicated in the form of $\mathrm{z}$-score. This score must be in the range of the characteristic for native proteins, otherwise it can indicate an erroneous structure. After that, Ramachandran plots were generated using RAMPAGE server [21] to determine the overall quality of predicted and refined models.

\subsection{Molecular Docking to Highlight the Binding Affinity between the Chimeras and Mouse and Human TLR Receptors}

For molecular docking, we used ClusPro2.0, which utilizes the Fourier correlation algorithm, filtering out the models with the amalgamation of desolvation and electrostatic energies. On the basis of the lowest binding energy, docked complexes were selected for further analysis [22]. The evaluation of the binding affinity between the refined constructs (chimeras A and B) and mouse and human toll-like receptors (TLRs) 3 and 4 was performed. The tertiary structures of TLR3 and TLR4 were retrieved from the PDB database [23,24] — for TLR3 we used id:3CIG (mouse) and id:2A0Z (human). Regarding TLR4, id:5IJB and id:4G8A were used, corresponding to mouse and human, respectively.

\subsection{Chimera Proteins Synthesis}

The proteins (chimeras A and B) were synthetized by GenScript company; the genes were constructed, cloned, and expressed in prokaryote system (Escherichia coli) according to the manufacturer. The purification was performed by nickel column followed by characterization using SDS-PAGE and Western blot (Figure S2). The purified proteins were endotoxin free $(<1 \mathrm{EU} / \mu \mathrm{g})$ and with purity higher than $90 \%$ by SDS-PAGE. The endotoxins were measured according to the Food and Drug Administration FDA-approved techniques for endotoxin detection, therefore Genscript used Limulus amoebocyte lysate (LAL) assay. The specific LAL kinetic turbidimetric form was performed, which can detect down to $0.01 \mathrm{EU} / \mathrm{mL}$.

\subsection{Parasites}

Promastigotes of L. infantum, strain OP46 (MCAN/BR/2008/OP46), maintained by passage in Syrian golden hamsters were cultured at $22-24{ }^{\circ} \mathrm{C}$ in medium LIT (liver infusion tryptose) with $100 \mathrm{U}$ of penicillin G sodium and $100 \mu \mathrm{g}$ of streptomycin sulfate per milliliter, and were sub-cultured in the same medium at an average density of $1 \times 10^{8}$ cells/ml as described by [25]. The parasites were used for soluble Leishmania antigen (SLA) preparation, as described by [26], as well as for mice experimental challenge.

\subsection{Immunization Regimens and Challenge of the Mice}

For vaccine efficacy studies, eight 6- to 8-week-old female BALB/c mice per group (Centro de Ciência Animal (CCA) facility) were randomized by corporal weight and immunized three times biweekly subcutaneously in the back with $100 \mu$ of vaccine formulations per mouse. The experimental groups were divided in SAL (animals that received sterile saline, $0.9 \% \mathrm{NaCl}, \mathrm{pH} 7.2-7.4$ ), SAP (animals inoculated with $60 \mu \mathrm{g}$ of saponin), ChiA+SAP (animals that received $10 \mu \mathrm{g}$ of the chimeric protein A associated with $60 \mu \mathrm{g}$ of saponin), and ChiB+SAP (animals inoculated with $10 \mu \mathrm{g}$ of chimeric protein $\mathrm{B}$ associated with $60 \mu \mathrm{g}$ of saponin). The doses were stablished on the basis of certain studies using 
chimeric proteins where $10 \mu \mathrm{g}$ of the chimeric proteins per dose was in the average [27,28]. Mice were challenged by injecting $1 \times 10^{7}$ of stationary L. infantum strain OP46 promastigotes intravenously, 15 days after the last immunization.

\subsection{Analyses of Polyfunctional T cell Phenotypes}

Fourteen days after the last immunization, polyfunctional $\mathrm{T}$ cell phenotypes were assessed in splenocytes of mice. The evaluation was performed before infection because we wanted to analyze the vaccine immune responses triggered in BALB/C mice in more detail, and because the identification of these poly-functional $\mathrm{T}$ cells is more evident after the last immunization but before the infection [6,29]. Cell suspensions were incubated in RPMI supplemented with 1\% L-glutamine and 10\% fetal bovine serum and plated in 96-well round-bottom (Costar, USA) culture plates at a concentration of $5 \times 10^{5}$ cells per well. Cells were cultured for $24 \mathrm{~h}$ at $37{ }^{\circ} \mathrm{C}$ with $5 \% \mathrm{CO}_{2}$ in the presence of SLA $(50 \mu \mathrm{g} / \mathrm{ml})$. Brefeldin A (SIGMA) was added $(10 \mu \mathrm{g} / \mathrm{ml})$ at $20 \mathrm{~h}$ of incubation. Afterwards, cells were blocked with anti-mouse CD16/CD32 (Mouse BD FC block, 0,5 $\mu \mathrm{g} /$ well) harvested, washed, treated with Phosphate buffer saline (PBS) plus an inert protein (serum albumin 5\%), and stained with anti-mouse CD3 FITC (clone 145.2C11), anti-mouse CD4 BV605 (clone RM4-5), anti-mouse CD8 $\alpha$ BV786 (clone 53-6.7), anti-mouse CD62L BV510 (clone MEL-14), and anti-mouse CD44 APC (clone IM7) (BD Biosciences Bioscience, USA) at room temperature for 30 minutes. Cells were fixed with FACS fixing solution (10 g/L paraformaldehyde, $10.2 \mathrm{~g} / \mathrm{L}$ sodium cacodylate, and $6.63 \mathrm{~g} / \mathrm{L}$ sodium chloride, $\mathrm{pH} 7.2$ ), washed, and treated with PBS buffer containing 0.5\% saponin for permeabilization. Cells were stained with anti-mouse IFN- $\gamma$ AF700 (clone XMG1.2), anti-mouse tumor necrosis factor (TNF- $\alpha$ )PE-Cy7 (clone LG.3A10), and anti-mouse IL-2 PE (clone JES6-5H4) (BD Biosciences Bioscience, San Jose, CA, USA). Cells were acquired (300,000 events) on LSR Fortessa cytometer (BD Biosciences, USA) using FACSDiva software. For analysis in FlowJo software, dead cells were excluded after FVS450 stain and alive cells were gated for $\mathrm{CD}^{+}$and $\mathrm{CD}^{+} \mathrm{T}$ cells and intracellular cytokine production. Polyfunctional cells were analyzed through the Boolean gate strategy.

\subsection{Proliferation Assay and Intracellular Cytokine Stain}

The proliferation of antigen experienced $\mathrm{T}$ cells was assessed by Carboxyfluorescein diacetate succinimidyl ester (CFSE) assay, 30 days after mice challenge, as described by [11]. Briefly, spleen's cell suspensions were incubated in $5 \mu \mathrm{M}$ CFDA-SE and the labeled cells were washed thoroughly before plating in 96-well round-bottom culture plates at a concentration of $5 \times 10^{5}$ cells per well. Cells were cultured for 5 days at $37^{\circ} \mathrm{C}$ with $5 \% \mathrm{CO}_{2}$ in the presence of SLA $(50 \mu \mathrm{g} / \mathrm{ml})$. After incubation, cells were treated with $10 \mu \mathrm{g} / \mathrm{ml}$ of brefeldin A (Sigma) for $4 \mathrm{~h}$. Afterwards, cells were blocked with anti-mouse CD16/CD32 (0.5 $\mu \mathrm{g} /$ well) and harvested, washed, treated with PBS and an inert protein (serum albumin 5\%), and stained with anti-mouse CD3 BV650 (clone 145.2C11), anti-mouse CD4 BV605 (clone RM4-5), and anti-mouse CD8 $\alpha$ BV786 (clone 53-6.7) (BD Biosciences Bioscience, USA) at room temperature for 30 minutes. Cells were fixed with FACS fixing solution $(10 \mathrm{~g} / \mathrm{L}$ paraformaldehyde, $10.2 \mathrm{~g} / \mathrm{L}$ sodium cacodylate, and $6.63 \mathrm{~g} / \mathrm{L}$ sodium chloride, $\mathrm{pH}$ 7.2), washed, and permeabilized. Cells were stained with anti-mouse IFN- $\gamma$ AF700 (clone XMG1.2), anti-mouse TNF- $\alpha$ PE-Cy7 (clone LG.3A10), and anti-mouse IL-2 PE (clone JES6-5H4) (BD Biosciences Bioscience, USA). Cells were acquired (300,000 events) on LSR Fortessa cytometer (BD Biosciences, USA) using FACSDiva software. For analysis in FlowJo software, dead cells were excluded after FVS780 stain and alive cells were gated for CFSE-stained $\mathrm{CD}^{+}$and $\mathrm{CD}^{+} \mathrm{T}$ cells and intracellular cytokine production.

\subsection{Analyses of Memory $T$ cell Phenotypes}

Central and effector memory T cells were analyzed 30 days post-challenge, as described by [11]. Splenocytes from animals were plated at $5 \times 10^{5}$ cells per well in duplicate in 96 -well round-bottom plates. Cells were treated with the same conditions described above. After 5 days of culture, cells were then prepared for flow cytometry analysis. Samples were blocked with anti-mouse CD16/CD32 (0.5 $\mu \mathrm{g} / \mathrm{well})$ 
and stained with surface markers at room temperature using the following antibodies: anti-mouse CD3 FITC (clone 17A2), anti-mouse CD4 BV605 (clone RM4-5), anti-mouse CD8 $\alpha$ PerCP-Cy5.5 (clone 53-6.7), anti-mouse CD44 APC (clone IM7), anti-mouse CD45RA BV711 (clone 14.8), anti-mouse CD62L AF700 (clone MEL-14), anti-mouse CD127 BV510 (clone SB/199), and anti-mouse CD197 BV421 (clone 4B12). The events were acquired (300,000 cells) on an LSR Fortessa cytometer (BD Biosciences) using FACSDiva software. For analysis, dead cells were excluded after FVS780 stain and live cells were used for further analyses.

\subsection{Evaluation of the Parasite Burden in the Spleen by Quantitative PCR}

Parasite burden in the spleen was analyzed 30 days after infection by real-time PCR (qPCR) quantification, as described by [30]. Briefly, at the end of the study, the mice were euthanized, and the spleens were extracted and used for genomic DNA isolation with the CTAB reagent. The L. infantum spleen burden was assessed by PCR quantification of DNA polymerase (forward primer: 5'-TGTCGCTTGCAGACCAGATG-3'; reverse primer: 5'-GCATCGCAGGTGTGAGCAC-3'; Taqman probe: VIC 5'-AGGAAACCTGTGGAGCC-3' MGB NFQ). The amounts of mouse chromosomal DNA in extracted spleen were analyzed using murine TNF- $\alpha$ primers (5TCCCTCTCATCAGTTCTATGGCCCA-3; 5-CAGCAAGCATCTATGCACTTAGACCCC-3) that amplify a 170 bp product. The PCR reactions were conducted as follows: one incubation step at $50{ }^{\circ} \mathrm{C}$ for $2 \mathrm{~min}$ and an initial denaturation step at $95^{\circ} \mathrm{C}$ for $10 \mathrm{~min}$, followed by 40 cycles of denaturation at $95{ }^{\circ} \mathrm{C}$ for $15 \mathrm{~s}$ and annealing-extension at $60^{\circ} \mathrm{C}$ for $1 \mathrm{~min}$. All samples were run on MicroAmp optical 96-well reaction plates (Applied Biosystems) sealed with MicroAmp optical adhesive film (Applied Biosystems). Each 96-well reaction plate contained a standard curve in triplicate (efficiency, 96.0\%; $\left.r^{2}=0.99\right)$ in duplicate samples. The result was expressed as number of amastigotes DNA copies per spleen of mice.

\subsection{Statistical Analysis}

The data were analyzed through Graph Pad Prism 8.0 software and expressed as mean plus/minus standard deviation (SD). First, the normality of the data was assessed using the Shapiro-Wilk test and statistical differences were analyzed by one-way ANOVA and Kruskal-Wallis test followed by Dunnett's and Dunn's multiple comparison tests, respectively. Correlation analyses were performed by Pearson's $r$ test. Differences were considered significant when $p$-value $<0.05$.

\section{Results}

\subsection{In Silico Construction of the Chimeras $A$ and $B$}

Herein, a total of 12 epitopes (ligands for mouse and human MHC class I and II alleles) were predicted to construct chimera A and chimera B. These epitopes were mapped in the sequence of nine proteins described in the literature as potential vaccine candidates for VL. The peptides are represented in Table 1, where it can be seen that most of them were highly conserved across L. donovani and L. major species. To construct the chimeras, the epitopes were repeated in tandem to enhance the immunogenicity, and GPGPG sequence was used as a linker. The final constructions of the chimeras were predicted to be highly antigenic (predicted probability of antigenicity chimera $\mathrm{A}=0.896793$ and chimera $B=0.790044$ ), and they were also revealed to be nonallergic in nature. Prediction by SVM method based on amino acid composition (chimera A score $=-0.96747231$ and threshold $=-0.4$; chimera B score $=-0.55381796$, threshold $=-0.4$ ). Prediction was based on the SVM method which was based on dipeptide composition (chimera A score $=0.27467095$, threshold $=-0.2$; chimera B score $=0.14230073$ and threshold $=-0.2$ ). For predictions based on BLAST analyses, no hits were found for both chimera sequences and they did not contain experimentally proven Immunoglobulin $\mathrm{E}$ (IgE) epitope. 
Table 1. MHC class I and II epitopes of known Leishmania infantum proteins that have been shown as candidate vaccines for leishmaniasis. The amino acid sequence, alleles, and conservancy of these promiscuous epitopes are represented in the table. The epitopes were selected through an immunoinformatics pipeline describe by $[9,11]$ and they showed a high score for the algorithms NetMHC, NetCTL, and NetMHCII.

\begin{tabular}{|c|c|c|c|c|c|c|c|c|c|c|c|}
\hline \multirow[t]{2}{*}{ Chimera } & \multirow{2}{*}{ Protein } & \multirow[t]{2}{*}{ Epitope Sequence } & \multirow{2}{*}{\multicolumn{5}{|c|}{ MHC Class I and II Alleles }} & \multicolumn{4}{|c|}{$\begin{array}{l}\text { Conservancy of the Selected Epitope across Leishmania } \\
\text { Species (\%) }\end{array}$} \\
\hline & & & & & & & & L. donovani & L. major & L. amazonensis & L. braziliensis \\
\hline \multirow{12}{*}{ Chimera $\mathbf{A}$} & \multirow{2}{*}{ Histone protein (H2A) } & KKRCRLNPR & H2-Dk & & & & & 100 & 89 & 100 & 66 \\
\hline & & DDISSLLKNVTLSHS & HLA-DRB1*1302 & HLA-DRB1*0101 & HLA-DRB1*0401 & HLA-DRB1*0404 & HLA-DRB1*1501 & 100 & 87 & 100 & 66 \\
\hline & \multirow{2}{*}{ Acid ribosomal protein P2 (LiP2a) } & AAKMSAMPAASSGAA & HLA-DRB1*0901 & HLA-DRB1*0101 & & & & 100 & 100 & 100 & 93 \\
\hline & & MSTKYLAAY & HLA-A*01 & HLA-A*26 & HLA-B*62 & HLA-A*03 & HLA-B*58 & 100 & 100 & 100 & 100 \\
\hline & \multirow{2}{*}{ Acid ribosomal protein $\mathrm{P0}$ (LiP0) } & VDAFKNLLAVSVATSYEF & HLA-DRB1*0101 & HLA-DRB1*0701 & HLA-DRB1*1501 & HLA-DRB1*1302 & & 100 & 100 & 100 & 94 \\
\hline & & AHRVKAPAR & H2-Dk & & & & & 100 & 100 & 100 & 89 \\
\hline & \multirow{3}{*}{$\begin{array}{l}\text { Leishmania homologue of } \\
\text { activated C kinase (LACK) }\end{array}$} & WSADGNTLY & HLA-A*01 & HLA-A*26 & HLA-B*62 & HLA-B*58 & & 100 & 100 & 100 & 100 \\
\hline & & DRSIRMWDLRNGQCQ & HLA-DRB4*0101 & HLA-DRB1*1501 & & & & 100 & 100 & 100 & 93 \\
\hline & & ATERSLSVY & HLA-A*01 & HLA-A*26 & HLA-B*62 & & & 100 & 100 & 100 & 78 \\
\hline & \multirow{3}{*}{ Cysteine peptidase C (CPC) } & GYLVSGKSL & HLA-A*24 & H2-Kd & & & & 100 & 100 & 100 & 78 \\
\hline & & WTASADNGY & HLA-A*01 & HLA-A*26 & HLA-B*62 & HLA-B $* 58$ & & 100 & 100 & 100 & 89 \\
\hline & & LVKYKGGTSYSVKGE & HLA-DRB1*0101 & HLA-DRB1*0701 & HLA-DRB1*1501 & & & 100 & 100 & 100 & 60 \\
\hline \multirow{12}{*}{ Chimera B } & \multirow{3}{*}{ Cysteine peptidase A (CPA) } & MTEDYMGMY & HLA-A*01 & HLA-A*26 & B62 & & & 89 & 100 & 67 & 100 \\
\hline & & AKRRRLPTT & H2-Dk & & & & & 100 & 100 & 78 & 78 \\
\hline & & RPDFMNMTPRGVPLE & HLA-DRB1*0101 & HLA-DRB1 ${ }^{*} 0701$ & HLA-DRB1*1501 & HLA-DRB1*1302 & HLA-DRB5*0101 & 100 & 87 & 93 & 67 \\
\hline & \multirow{3}{*}{ Cysteine peptidase B (CPB) } & SKKFSHPSL & HLA-B*39 & & & & & 100 & 66 & 89 & 56 \\
\hline & & AGALVMGTALLTESA & HLA-DRB1*0101 & HLA-DRB1*0404 & HLA-DRB1*1302 & & & 100 & 60 & 80 & 67 \\
\hline & & RTDRQSCLY & HLA-A*01 & HLA-B*58 & HLA-A*03 & & & 100 & 78 & 89 & 78 \\
\hline & \multirow{3}{*}{$\begin{array}{c}\text { Surface antigenic protein } \\
\text { (PSA-50S) }\end{array}$} & DSWSRLQGLTSLTLS & HLA-DRB1*0101 & HLA-DRB1*1501 & & & & 53 & 87 & 53 & 53 \\
\hline & & LPPEWAAMP & H2-Dd & & & & & 78 & 89 & 78 & 78 \\
\hline & & LTDERTCLV & HLA-A*01 & HLA-A*02 & & & & 67 & 100 & 78 & 67 \\
\hline & \multirow{3}{*}{ Amastigote protein A2 (A2) } & GKGLRAPPL & H2-Dk & & & & & 100 & 100 & 78 & 56 \\
\hline & & SQAGDVFAL & HLA-B*39 & HLA-B*62 & HLA-B $* 44$ & HLA-A*02 & HLA-B*27 & 100 & 89 & 78 & 56 \\
\hline & & GPHLRGGAVTSSVVT & HLA-DRB1*0101 & HLA-DRB1*0701 & & & & 100 & 87 & 67 & 60 \\
\hline
\end{tabular}


Regarding physicochemical properties, chimera A was found to have $40 \mathrm{kDa}$ of molecular weight and Chimera B has $38 \mathrm{kDa}$. The theoretical isoeletric points $(\mathrm{pI})$ for the chimeras A and B were found to be 9.8 and 9.57, respectively, showing a basic nature. For chimeras A and B, an in silico estimated half-life of $30 \mathrm{~h}$ in mammalian reticulocytes and 20 and $10 \mathrm{~h}$ in yeast and E. coli, respectively, was observed. Both the chimeras are hydrophilic in nature according to grand average of hydropathicity (GRAVY).

\subsection{Tertiary Structure Prediction and Binding Affinity between the Chimeras and Mouse and Human TLR Receptors}

RaptorX webserver was used to predict the tertiary structure and three-dimensional (3D) model of the chimera proteins. Further, the refinement of the chimeras' models was assessed using Galaxy Refine tool. To validate the 3D models, RAMPAGE and ProSA were used, and the initial model of the chimeras A and B showed $85.4 \%$ and $88.5 \%$ of residues, respectively, in the favored regions, whereas after refinement, the models reached to $90.1 \%$ and $92.7 \%$, respectively. The z-score returned for chimera A was -2.02 and for chimera B it was -4.01 , and this showed that the quality of the predicted model is acceptable (Figure 1a,b).

After the molecular docking of chimera proteins and human (Figure 2a) and mice (Figure 2b) TLR3/TLR4 receptors, several models were generated for the eight complexes. Among them, we selected only models that presented the lowest energy and where the receptors were properly occupied by the constructs; thus, Figure 2 shows the best-docked complexes. Toll-like receptors (TLRs) are a group of receptors that can recognize pathogen-associated molecular patterns (PAMPs), and they play a crucial role in modulating immune response. TLR4 and TLR3 are expressed on cell membrane surface and on endosomes, respectively. Their activation results into functioning of intracellular signalling pathway of nuclear factor kappa-B (NF-kB) and cytokine production, leading to innate immune system activation and ultimately long-lasting adaptive immunity that is important against various pathogens [31]. Thus, we wanted to measure in silico the capacity of the chimeras to bind those TLRs, suggesting that vaccines should have the capacity to enter into immune cells and be able to trigger an immune response. 
(a)

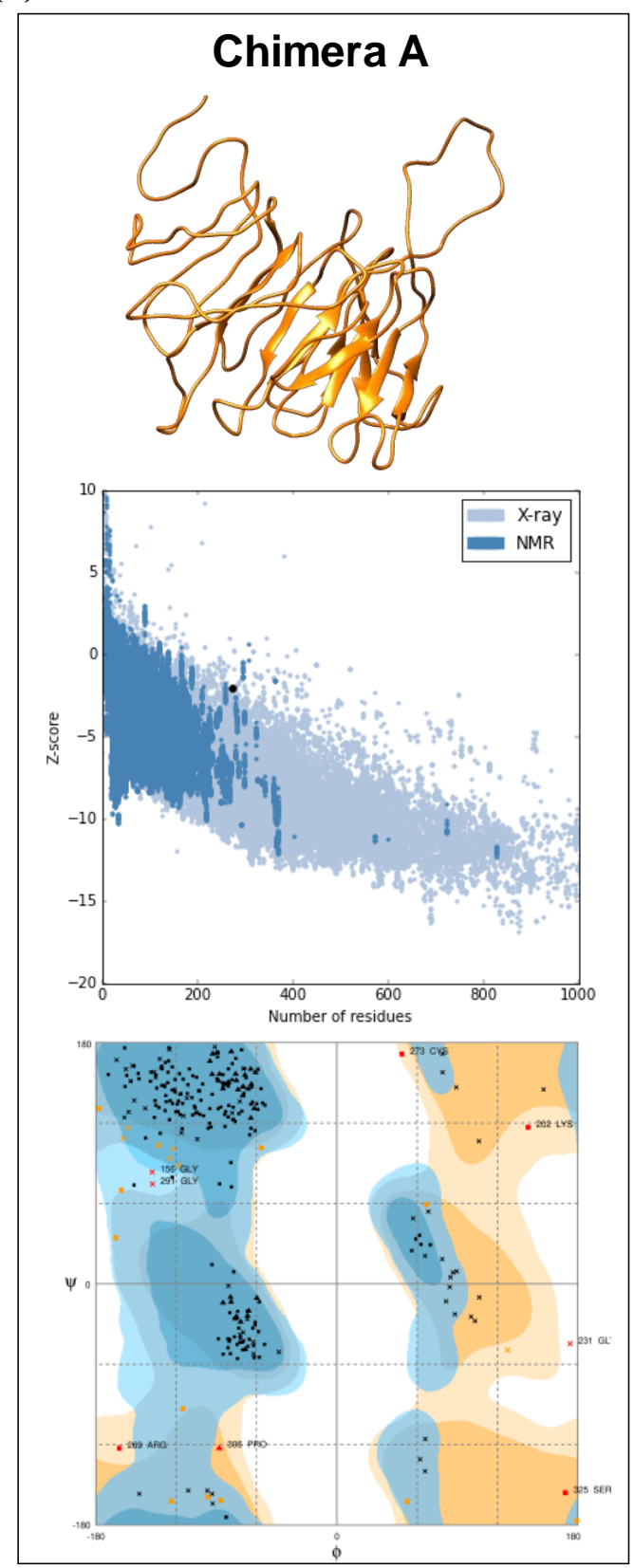

(b)

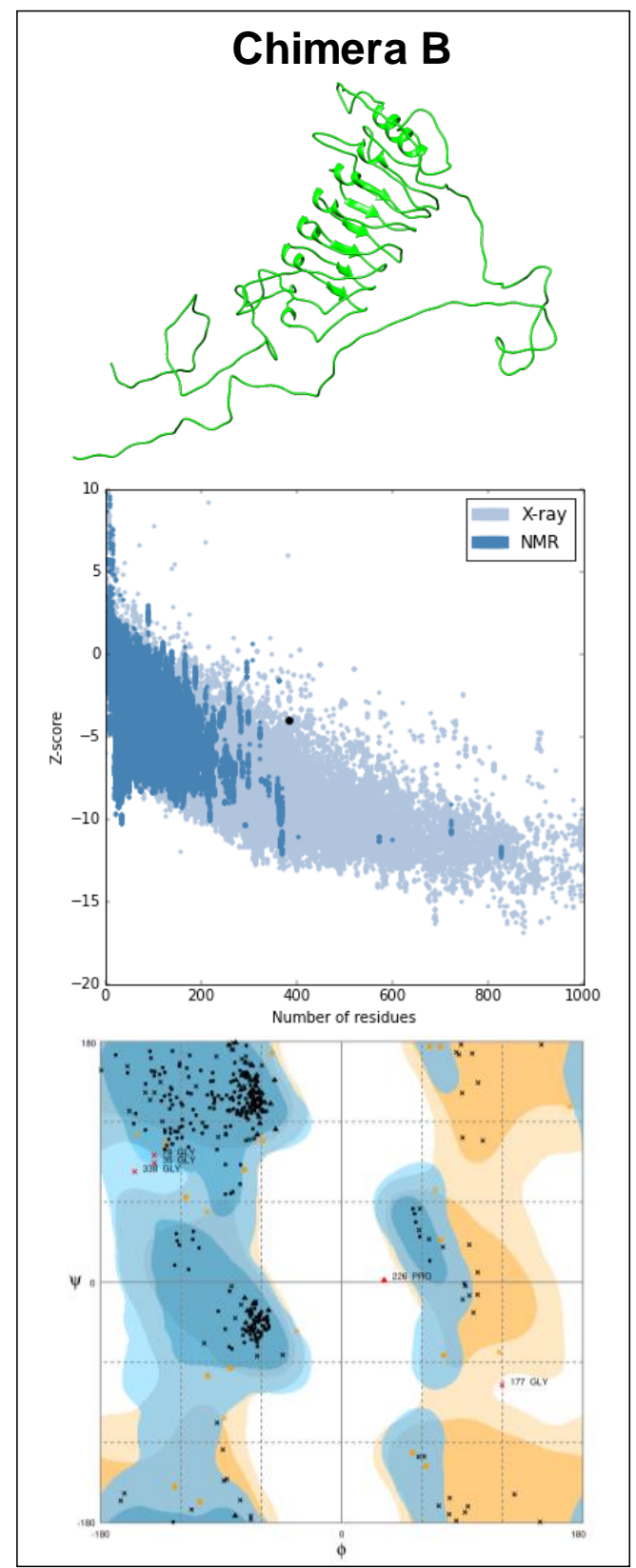

Figure 1. Illustrative representation of $3 \mathrm{D}$ structures for chimeras $\mathrm{A}$ and $\mathrm{B}$ and the validation parameters provided by Rampage and ProSA web servers. Chimera A (a) is represented by orange color and chimera B (b) is represented by green color. ProSA analysis and Ramachandran diagrams are represented in the figure for both chimeras (above 3D structures). The quality of the models is given by the z-score (-3.05) predicted by the ProSA, whereas Ramachandran diagrams show the distribution of the amino acid in favored, allowed, and disallowed regions. 


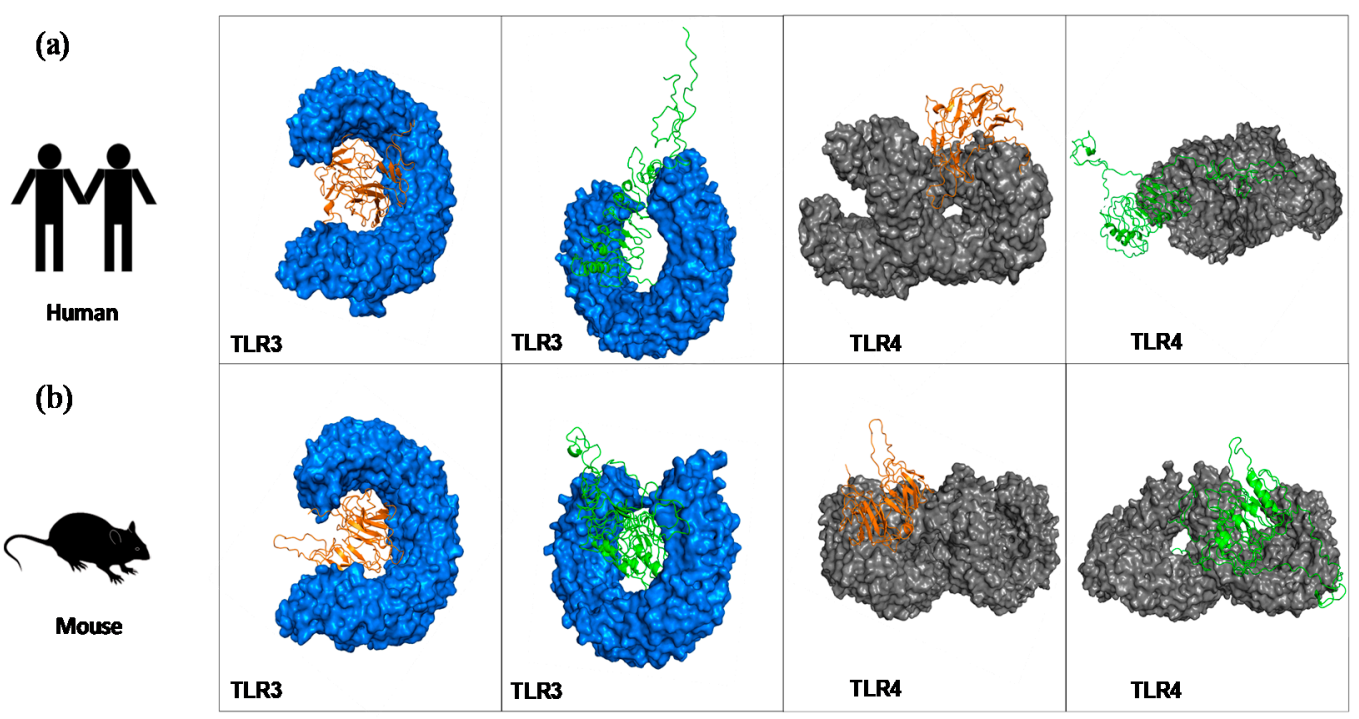

Figure 2. Interaction of refined models for chimeras A and B with toll-like receptors using molecular docking (ClusPro2.0 web server). Representation of the best docked-complex between chimeras and human (a) and mouse (b) toll-like receptor (TLR)3 (blue) and TLR4 (grey). Chimera A (a) is represented by orange, chimera B is represented by green.

3.3. Chimeras A and B Designed by Immunoinformatics Tools Elicited a Different Pattern of Polyfunctional T Cells in the Spleen of Immunized Mice

In this step, BALB/c mice were immunized (2 weeks of interval) with the chimeras, and the animals were sacrificed 14 days after the last dose (Figure 3a). To determine the capacity of the chimeras to elicit and develop polyfunctional central and effector memory cells, single, double, and triple intracellular cytokine productions were evaluated in T cells using multicolor flow cytometry. The gating strategy is shown in Figure $3 \mathrm{~b}$. The analysis of single-cell cytokine production indicated that IFN- $\gamma$ and TNF- $\alpha$ produced by central memory $(\mathrm{CM}) \mathrm{CD}^{+} \mathrm{T}$ cells (Figure $3 \mathrm{c}$ ) were significantly higher in the ChiA+SAP and $\mathrm{ChiB}+\mathrm{SAP}$ groups when compared to the control groups (SAL, SAP). There was no difference for IL-2 single production between the groups. On the other hand, the double cytokine production (IL- $2+$ IFN- $\gamma$ IL- $2+$ TNF- $\alpha$ and IFN- $\gamma+$ TNF- $\alpha$ ) was higher in the vaccinated groups comparing to SAL and SAP, although there were no statistical differences in the triple cytokine production in the immunized groups. For effector memory (EM) $\mathrm{CD}^{+} \mathrm{T}$ cells (Figure $3 \mathrm{~d}$ ), $\mathrm{ChiB}+\mathrm{SAP}$ was able to induce higher single (IFN- $\gamma$ and TNF- $\alpha$ ), double (IL- 2 + TNF- $\alpha$ and IFN- $\gamma+$ TNF- $\alpha$ ), and triple (IFN- $\gamma+$ IL-2 + TNF- $\alpha$ ) cytokine production when compared to SAL and SAP. Regarding the subpopulation of CM $\mathrm{CD}^{+} \mathrm{T}$ cells (Figure $3 \mathrm{e}$ ), it a higher production of triple cytokine in the cells of the immunized mice (ChiA+SAP and ChiB+SAP) was observed when compared to SAL and ChiB+SAP-immunized mice in comparison to SAP group. In addition, $\mathrm{ChiB}+\mathrm{SAP}$ promoted an enhancement in the percentage of $\mathrm{CM} \mathrm{CD}^{+}$producing double cytokines (IL-2 + TNF- $\alpha$ and IFN- $\gamma+\mathrm{TNF}-\alpha$ ) when compared to the control groups. Changes in the patterns of cytokine production were found in EM CD8 ${ }^{+} \mathrm{T}$ cells (Figure 3f), where ChiB+SAP induced higher frequency of cells producing single (except IL-2), double, and triple cytokines when compared to SAL and SAP. Taken together, these data show that the chimeric vaccines constructed through immunoinformatics induced an immunogenicity and increased the polyfunctionality central and effector $\mathrm{T}$ cell subpopulations. 
(a)

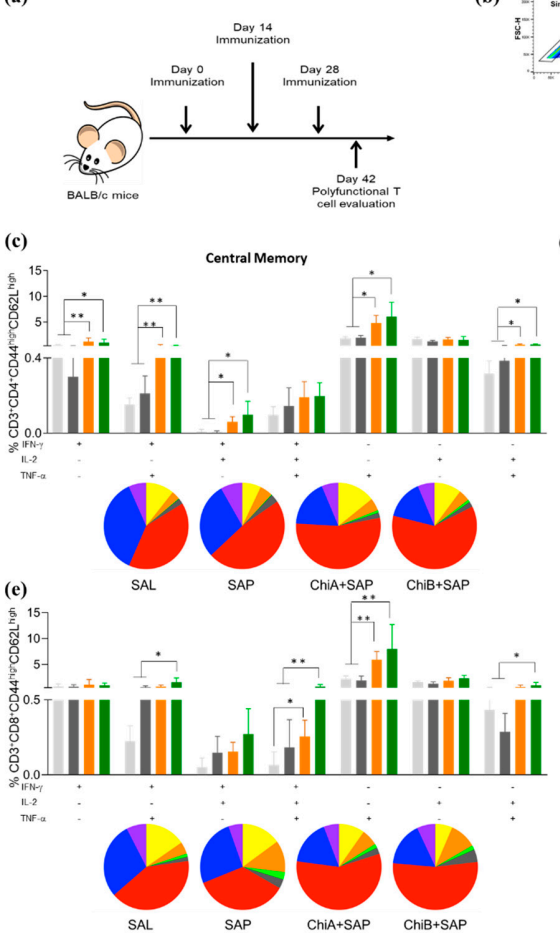

(b)
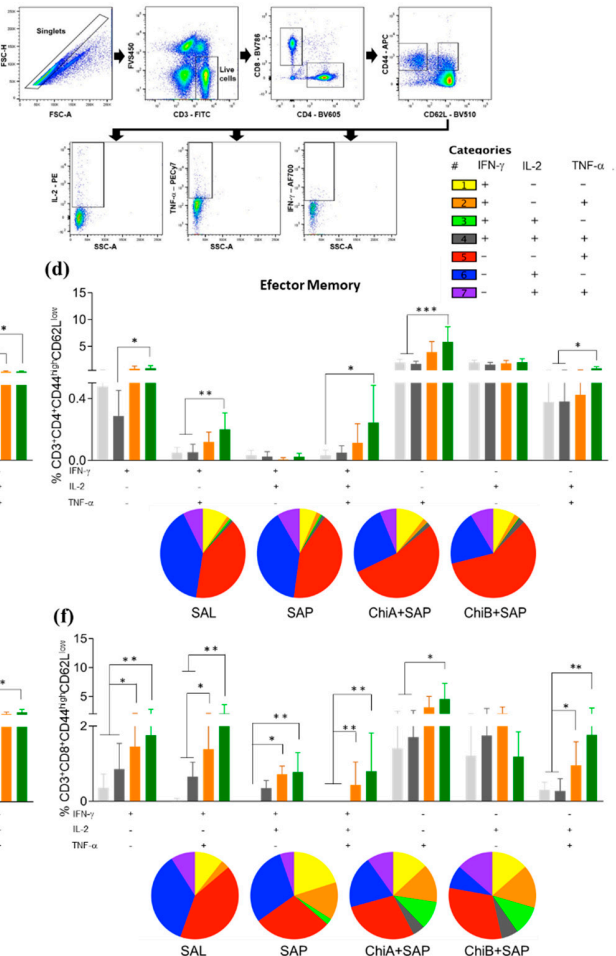

Figure 3. Percentage of polyfunctional T cells in spleens of immunized mice with ChiA+SAP (animals that received $10 \mu \mathrm{g}$ of the chimeric protein A associated with $60 \mu \mathrm{g}$ of saponin) and ChiB+SAP (animals inoculated with $10 \mu \mathrm{g}$ of chimeric protein B associated with $60 \mu \mathrm{g}$ of saponin). Polyfunctional $\mathrm{T}$ cells were evaluated by percentage of intracellular IL-2, TNF- $\alpha$, and IFN- $\gamma$ producing T cells (central and effector memory) at the same time. (a) BALB/c mice were immunized three times and polyfunctional $\mathrm{T}$ cells were assessed in spleen 14 days after the last immunization using multicolor flow cytometry. (b) Representative plot of the gating strategy to characterize the multifunctional $\mathrm{T}$ cell producers of intracellular IFN- $\gamma$, TNF- $\alpha$, and IL-2 using the Boolean gate strategy. (c) The percentage of $\mathrm{CD}^{+}{ }^{+} \mathrm{CD} 4{ }^{+} \mathrm{CD} 44^{\text {high }} \mathrm{CD} 62 \mathrm{~L}^{\text {high }}$ and $(\mathbf{d}) \mathrm{CD}^{+}{ }^{+} \mathrm{CD} 4^{+} \mathrm{CD} 44^{\text {high }} \mathrm{CD} 2 \mathrm{~L}^{\text {low }}$ cells producing single, double, and triple cytokines after in vitro stimulation with SLA (soluble Leishmania antigen). (e) The percentage of $\mathrm{CD}^{+} \mathrm{CD} 8{ }^{+} \mathrm{CD} 44^{\text {high }} \mathrm{CD} 62 \mathrm{~L}^{\text {high }}$ and (f) $\mathrm{CD} 3^{+} \mathrm{CD} 8{ }^{+} \mathrm{CD} 44^{\text {high }} \mathrm{CD} 62 \mathrm{~L}^{\text {low }}$ producing single, double, and triple cytokines in vitro after stimulation with SLA. The groups SAL (animals that received sterile saline, $0.9 \% \mathrm{NaCl}$, pH 7.2-7.4), SAP (animals inoculated with $60 \mu \mathrm{g}$ of saponin), ChiA+SAP, and $\mathrm{ChiB}+\mathrm{SAP}$ are represented by the colors light grey, dark grey, orange, and green, respectively, and pizza graphs represent the pattern of cytokine production. Data are expressed as means plus/minus standard deviation of two independent experiments $(n=8)$. Significant differences between the groups are represented by $p$-values: ${ }^{*} p$-value $<0.05,{ }^{* *} p$-value $<0.005,{ }^{* * *} p$-value $<0.0005$.

3.4. Chimeras a and B Not Only Induced Proliferation of T Cells but Also Enhanced the Production of Intracellular Cytokines by These Cells in the Spleen of Immunized Mice and after Being Challenged with L. Infantum

To evaluate the efficiency of the chimeras A and B to promote specific immune responses in vivo, BALB/c mice were immunized with three doses of chimeras with saponin (2-week intervals) and then challenged with promastigotas of L. infantum. Thirty days after challenge, they were euthanized (Figure 4a). The results of the proliferation of splenocyte and intracytoplasmic cytokine production were expressed as culture index stimulated by the control culture (SC/CC). The representative plot of the gating strategy for CFSE-labelled cells is shown in Figure S3. According to the data (Figure $4 \mathrm{~b}$ ), ChiA+SAP induced a higher $\mathrm{CD} 4^{+}$and $\mathrm{CD} 8^{+} \mathrm{T}$ cell proliferation when compared to $\mathrm{SAL}$ and $\mathrm{SAP}$ groups, whereas $\mathrm{ChiB}+\mathrm{SAP}$ induced a significant $\mathrm{CD} 4^{+} \mathrm{T}$ cell proliferation compared to SAL. Regarding intracellular IFN- $\gamma$ production by $\mathrm{CD} 4^{+}$and $\mathrm{CD} 8^{+} \mathrm{T}$ lymphocytes, we observed a significant increase in $\mathrm{ChiA}+\mathrm{SAP}$ and $\mathrm{ChiB}+\mathrm{SAP}$ compared to SAL and SAP groups (Figure 4c). 
Further, $\mathrm{ChiA}+\mathrm{SAP}$ and $\mathrm{ChiB}+\mathrm{SAP}$ were capable of increasing the production of TNF- $\alpha$ by $\mathrm{CD} 4^{+} \mathrm{T}$ cells and only ChiA+SAP increased the production of this cytokine by $\mathrm{CD} 8^{+} \mathrm{T}$ cells when compared to control groups (Figure 4d).

(a)

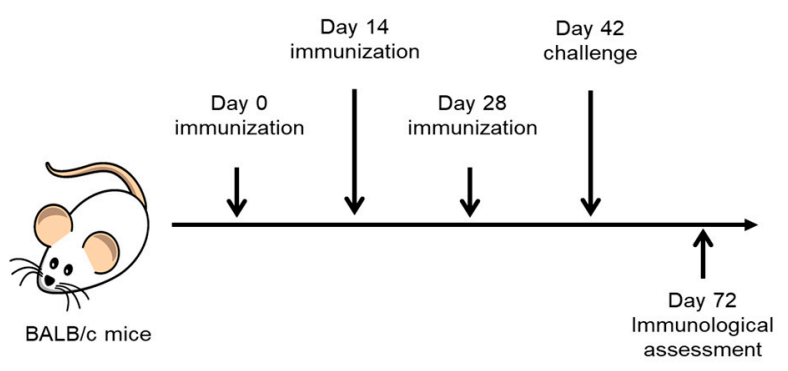

(b)

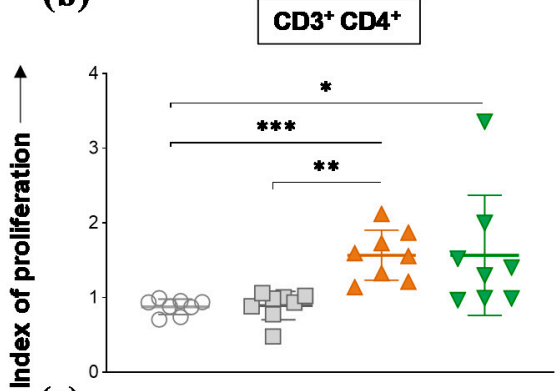

(c)

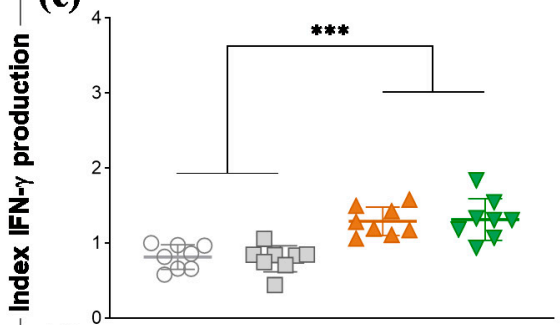

(d)

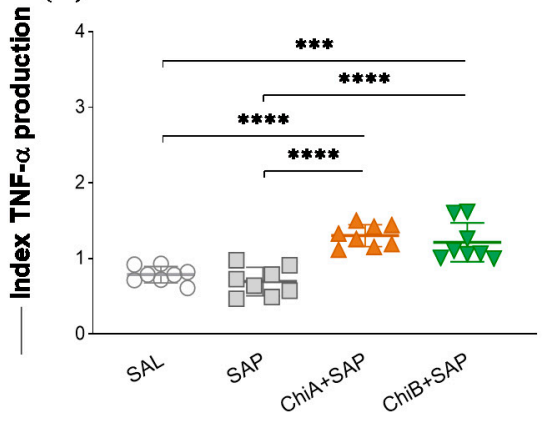

$\mathrm{CD3}^{+} \mathrm{CD}^{+}$
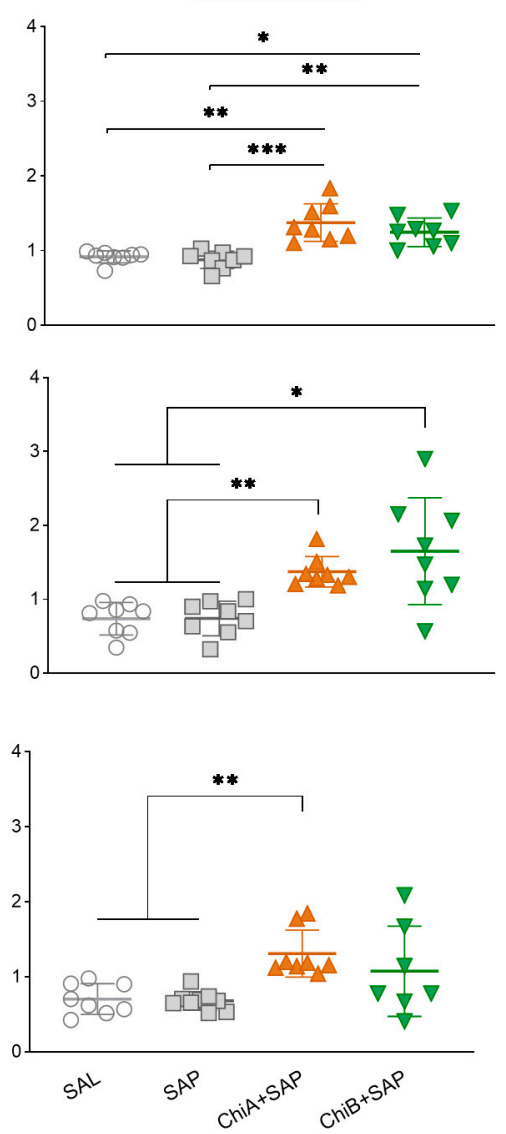

Figure 4. Splenic immune response after mice immunization with chimeric vaccines and challenge with $L$. infantum. (a) BALB/c mice were immunized three times and challenged with $L$. infantum promastigotes. Four weeks later, splenocytes were obtained and proliferation and intracellular cytokine production (IFN- $\gamma$ and TNF- $\alpha$ ) were assessed through flow cytometry. (b) Graphs represent the index of $\mathrm{T}$ cell proliferation (culture index stimulated by the control culture (SC/CC) ratio) of T-CD4 ${ }^{+}$and T-CD8 ${ }^{+}$ cells after in vitro stimulation with SLA (soluble Leishmania antigen). (c) Representation of IFN- $\gamma$ and (d) TNF- $\alpha$ production indexes (SC/CC ratio) of T-CD4 ${ }^{+}$and T-CD8 ${ }^{+}$cells after in vitro stimulation with SLA. Indexes were calculated on the basis of SLA-stimulated (SC) cultures divided by the control culture (CC). Data are expressed as means \pm SD of two independent experiments $(n=8)$. The $p$-values represent the difference between the groups: ${ }^{*} p$-value $<0.05,{ }^{* *} p$-value $<0.005,{ }^{* * *} p$-value $<0.0005$, and ${ }^{* * * *} p$-value $<0.0001$. 
3.5. Chimeras A and B Promoted a Strong Reduction in Parasite Burden and Developed Central and Effector Memory of T Cells in the Spleen of Immunized and Challenged Mice

We determined the capacity of these chimeric vaccines to protect immunized mice. For that, after the immunization, BALB/c mice were challenged and sacrificed after 30 days (Figure 5a). Total spleen DNA was used for the quantification of parasite burden. The results are shown in Figure $5 b$, where it can be seen that both chimeric vaccines promoted a significant reduction in parasite burden when compared to SAL and SAP groups. In this sense, this reduction was approximately $82 \%$ and $87 \%$ for ChiA+SAP and ChiB+SAP, respectively, when compared to the SAL group.

(a)

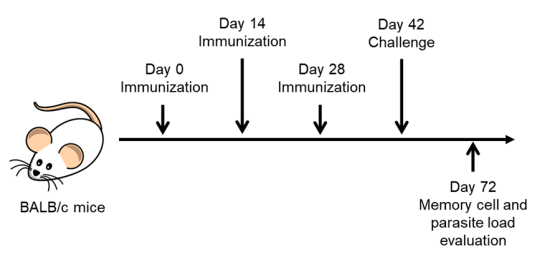

(c)

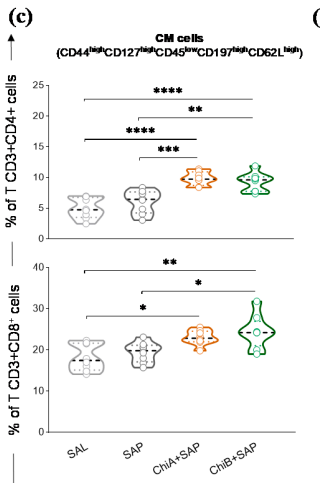

(d)

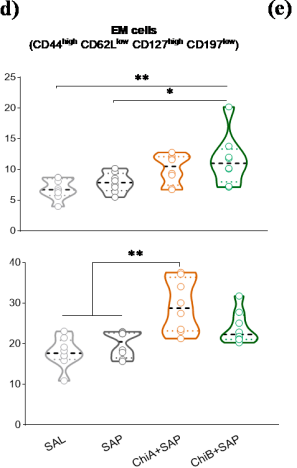

(b)

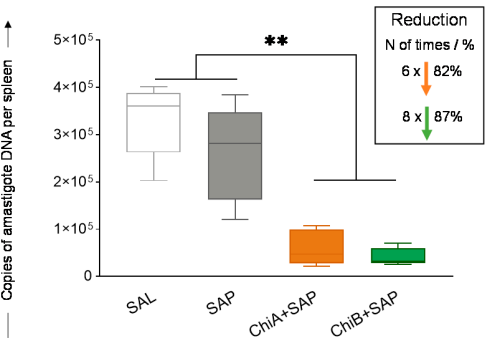

(e)

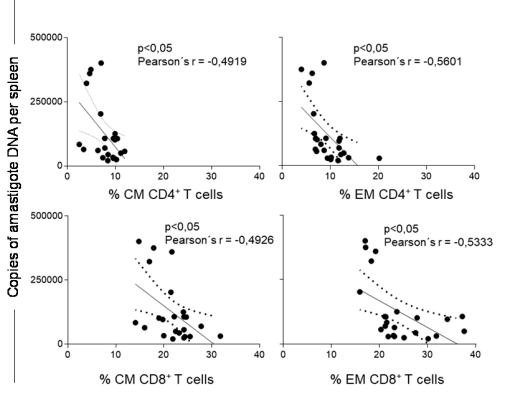

Figure 5. Parasite burden and generation of memory cells in the spleen of immunized mice with chimeric vaccines and challenged with L. infantum. (a) BALB/c mice were immunized three times and challenged with $L$. infantum promastigotes. Four weeks later, they were sacrificed for further analyses. (b) Parasite burden was assessed in the spleen using quantitative PCR and results are expressed in amastigote DNA copies per spleen. (c) Violin plots represent the percentage of central memory $\mathrm{T}$ cells $\left(\mathrm{CD}^{+} \mathrm{CD}^{+}\right.$or $\left.\mathrm{CD}^{+} \mathrm{CD} 127^{\text {high }} \mathrm{CD} 44^{\text {high }} \mathrm{CD} 45 \mathrm{RA}^{\text {low }} \mathrm{CD} 62 \mathrm{~L}^{\text {high }} \mathrm{C} 197^{\text {high }}\right)$ and (d) effector memory $\mathrm{T}$ cells $\left(\mathrm{CD}^{+} \mathrm{CD}^{+}\right.$or $\left.\mathrm{CD}^{+} \mathrm{CD} 6 \mathrm{~L}^{\text {low }} \mathrm{CD} 44^{\text {high }} \mathrm{CD} 127^{\text {high }} \mathrm{C} 197^{\text {low }}\right)$ in mice splenocytes after in vitro stimulation with SLA. (e) Correlation analyses between parasite load and frequency of $\mathrm{T} \mathrm{CD}^{+}$and $\mathrm{CD}^{+}$central memory (CM) and effector memory (EM) cells are shown by Pearson's $r$. Data on the graphs are represented as means \pm SD of two independent experiments $(n=8)$ and $p$-values represent the difference between the groups: ${ }^{*} p$-value $<0.05,{ }^{* *} p$-value $<0.005,{ }^{* * *} p$-value $<0.0005$, and ${ }^{* * * *} p$-value $<0.0001$.

Furthermore, to characterize memory phenotypes of T cells, we investigated CM and EM cells in the splenocyte cultures using a multicolor panel. CM T cell phenotypes were characterized by CD127 high $C D 44^{\text {high }}$ CD45 ${ }^{\text {low }}$ CD62 ${ }^{\text {high }}$ CD197 ${ }^{\text {high }}$ and EM cells were characterized by CD62L ${ }^{\text {low }}$ CD44 ${ }^{\text {high }}$ CD127 ${ }^{\text {high }}$ CD197low . The results demonstrated that, after challenge, the percentage of CM $\mathrm{CD}^{+}{ }^{+} \mathrm{T}$-cells was higher in ChiA+SAP and ChiB+SAP groups when compared to control groups (Figure 5c). Regarding the subpopulation $\mathrm{CD}^{+}$, it was observed that ChiA+SAP and ChiB+SAP enhanced the percentage of CM cells compared to SAL and ChiB+SAP, which also enhanced these cells when compared to SAP. Concerning EM cells, we found a high percentage of CD4 ${ }^{+} \mathrm{T}$ cells only in $\mathrm{ChiB}+\mathrm{SAP}$ compared to SAL and SAP. On the other hand, for CD8 ${ }^{+} \mathrm{T}$ cells, only ChiA+SAP was able to generate these memory cells when compared to the control groups (Figure $5 \mathrm{c}$ ). Moreover, we observed a negative correlation (Figure $5 \mathrm{~d}$ ) between the parasite burden and the percentage of CD4 ${ }^{+} \mathrm{CM}$ cells in 
the spleen (Pearson's $r=-0.4919 ; p$-value $<0.05)$. In addition, we found the same negative correlation for CD8 ${ }^{+} \mathrm{CM}$ cells (Pearson's $r=-0.4926, p$-value $\left.<0.05\right), \mathrm{CD}^{+}$EM cells (Pearson's $r=-0.5601$, $p$-value $<0.05$ ), and CD8 $8^{+}$EM cells (Pearson's $r=-0.5333$, $p$-value $<0.05$ ) (Figure 5e).

\section{Discussion}

The use of immunoinformatics capable of predicting immunodominant epitopes has been used in numerous studies. This methodology has already been described as being highly accurate for mapping immunogenic epitopes to Leishmania proteins $[2,9,11,32]$. Therefore, immunoinformatics can result in a huge gain for the design of multiepitope vaccines against neglected diseases, in this case, visceral leishmaniasis.

In this context, the present study focused on the design of multi-epitope chimeric vaccines that can afford a robust level of protective immunity against L. infantum. For that, we mapped potential $\mathrm{T}$ cell epitopes on nine known proteins that have immunogenic capabilities that have been described in the literature. Therefore, according to the computational methodology proposed by [9], we mapped the highest score epitopes provided by immunoinformatics concerning the histone H2A, Lip2a, Lip0, LACK, and CPC (chimera A) proteins, as well as CPA, CPB, PSA-50S, and A2 proteins (chimera B) (Figure S1). Thus, we could observe that the components chosen to construct both chimera A and chimera B are antigens that stimulate lymphocyte proliferation and IFN- $\gamma$ production. Further, the profile of cells stimulated with these antigens may also have a balanced Th1/Th2 polarization. This is observed by induction of humoral response with the production of immunoglobulins, but at the same time the antigens are able to trigger IFN- $\gamma$ production and in vitro cell proliferation of mouse splenocytes [33-40].

The final construct for chimeras A and B has epitopes with high score for the algorithms used, conservancy across L. donovani and L. major, and highly antigenic and non-allergic for dogs and/or human use. Their predicted physicochemical features demonstrated that they are stable, hydrophilic (negative values for GRAVY), and basic nature. The 3D structures were validated using Ramachandran plot and ProSA webserver, indicating that the quality of the models is satisfactory [41-45]. Various studies have been shown that chimera constructs that have an affinity to toll-like receptors (mainly TLR-3, TLR-4, and TLR-9) may have the ability to enhance the immune response against intracellular pathogens [42-46]. In this sense, we performed molecular docking showing the interaction between chimeras A and B with mouse and human TLR-3 and TLR-4. For the conformational stability of docked complexes, energy minimization was achieved to minimize the potential energy of the complete systems [44]. In summary, both evaluated chimeras interacted with mice and human TLR-3 and TLR-4 demonstrating, the in silico capacity to be immunogenic. The cloning and expression of the chimeras was well succeeded using E. coli system, as shown in Figure S2.

A critical feature of successful vaccines against Leishmania spp. is their ability to induce multifunctionality regarding cytokine production and immunological memory $[5,6,47]$. Therefore, we chose IFN- $\gamma$, TNF- $\alpha$, and IL-2, focusing on the objective of performing the multifunctional study to qualify both central and effector memory $\mathrm{T}$ cells. Some studies have already shown that multifunctional $\mathrm{T}$ cells that produce these cytokines are more effective when compared to individual production for parasite elimination and infection control $[5,6,10,48]$. Thus, our data reinforce that chimeras A and $\mathrm{B}$ associated with the adjuvant have this feature to change the patterns of cytokine production. These vaccines can elicit multifunctional $\mathrm{CD}^{+}$and $\mathrm{CD} 8^{+}$of $\mathrm{CM}$ and $\mathrm{EM} \mathrm{T}$ cells, which are crucial for the elimination of the parasite $[5,6,10,48]$. Additionally, the Chimeric vaccines trigged $\mathrm{T}$ lymphocyte activation through the proliferation of $\mathrm{CD}^{+}$and $\mathrm{CD} 8^{+}$subpopulations. The results of $\mathrm{T}$ lymphocyte proliferation in the vaccine groups after L. infantum stimulation further support the findings that IFN- $\gamma$ is released after this activation, and we can observe the generation of long-term immunological memory against Leishmania spp. [10,49-52]. Gamma interferon (IFN- $\gamma$, a cytokine considered central for protection against Leishmania spp.) is evaluated and investigated in practically all studies involving vaccines against leishmaniasis. This cytokine is critical for monitoring, screening, and designing 
effective vaccines against these intracellular protozoa $[4,10,32,53,54]$. Another effector cytokine is TNF- $\alpha$, which plays a crucial role in the control of intracellular protozoan [55,56]. Our data support the role of these cytokines to orientate a type 1 response that is paramount to protection against Leishmania spp. [6,57]. Moreover, our results suggest that the protection conferred by the chimeric multiepitope protein could be associated with IFN- $\gamma$ production by both T lymphocyte subpopulations.

To date, several vaccine candidates against the different types of leishmaniasis have been proposed and with promising results in murine models, but none of them have achieved the market for human immunization and VL prevention. This may be due to issues related to the different levels of immune memory generation that are currently agreed upon the guidelines for vaccine development in different research groups $[6,52,58,59]$. In our study, we characterized memory $\mathrm{T}$ cell phenotype in the spleen of the immunized animals. The results showed that both chimeric vaccines were able to trigger central memory in both $\mathrm{CD}^{+} \mathrm{T}$ lymphocytes and $\mathrm{CD} 8^{+} \mathrm{T}$ lymphocytes. Some studies have shown that these cells play a fundamental role in the immune response, being responsible for the renewal of immune system memory cells [60]. There is a compartmentalization of these memory cells, as demonstrated in studies in which central memory cells differentiate and expand in the spleen and may recirculate into secondary lymphoid organs [5]. Regarding the findings of effector memory cells, only ChiB+SAP was able to generate $\mathrm{CD} 4^{+} \mathrm{EM}$ T cells, and ChiA+SAP promoted an increase in $\mathrm{CD} 8^{+} \mathrm{EM}$ T cells. Effector memory cells have the important capacity to migrate to the sites of infection [61]. Thus, the chimeric vaccines tested in this study were able to generate effector memory lymphocytes in the splenic compartment accompanied by a decrease in parasitic load on the organ.

It is difficult to point out which profile, central or effector memory, would be responsible for protection in experimental models. This is due to the heterogeneity of responses generated in leishmaniasis immunoprophylaxis studies in different species or animal models, in which there is no consensus on which memory $\mathrm{T}$ cell profile would characterize the vaccine candidate as ideal or not [6]. Thus, it is believed that both profiles add a lot to this process of parasite control and elimination $[29,50,59]$. Our results corroborate with these studies, as we found negative correlation between the percentage of CM and EM T cells and parasite burden in the spleen. This shows that the augment of memory cells probably leads to parasite control and their elimination in the organs. In the splenic compartment there is the establishment of a chronic infection that occurs later and is not self-resolving as observed in the liver, which makes this organ one of the main targets in studies evaluating the efficacy of vaccines in BALB/c model [62]. Given the above information, our findings demonstrated an important parasite reduction in the spleen of vaccine groups of $82 \%$ and $87 \%$, respectively, for ChiA+SAP and ChiB+SAP.

Few studies evaluating polyepitope chimeric vaccines have been reported in the literature. Within the context of VL, there is a restricted number of studies on chimeric vaccines. Regarding challenges with L. infantum, parasite burden results in the spleen obtained by us were superior when compared to the $42 \%$ load reduction after 10 weeks of infection in a study conducted by [63]. Regarding the L. donovani challenge, the authors of [4] observed a surprising $91 \%$ reduction in parasite burden on the same organ after 21 days of infection. It is interesting to note that in this study we used $10 \mu \mathrm{g}$ per dose of each of the chimeras, much smaller amounts compared to other studies that used 20,25, 100, or even $200 \mu \mathrm{g}$ of multiepitope chimeric protein [10,63], indicating the higher capacity of our chimeras in generating immunogenicity, which must be directly associated with parasite control. We highlight the possibility of missing or omitting potential epitopes due to in silico prediction as a possible disadvantage noted in studies employing immunoinformatics. On the other hand, this methodology allows large-scale screening, leading to the mapping of important epitopes over a short period of time, which can potentially be very advantageous when used for leishmaniasis vaccines [3]. 


\section{Conclusions}

Taking all these findings together, this study is promising in the field of development of multiepitope chimeric vaccines for VL, being rationally designed using immunoinformatics and employing different computational approaches. Thus, the vaccines elicited multifunctional $\mathrm{T}$ cells and induced immunogenicity with $\mathrm{CD}^{+}$and $\mathrm{CD}^{+} \mathrm{T}$ lymphocyte proliferation and IFN- $\gamma$ and TNF- $\alpha$ production. Besides this, vaccines instigated the development of central memory and effector of $\mathrm{T}$ lymphocytes in mouse splenocytes, which led to a decrease in parasite load in splenic tissue. To achieve success in vaccine development for leishmaniasis, many rational approaches and new techniques for evaluation of polyfunctional and memory cells should be taken. In this sense, this study will contribute a large amount to the field of development of vaccines against VL, a critical neglected disease affecting thousands of people around the world.

\section{Patent}

The patent of the chimeric vaccines used in this study was deposited under the register number BR10201800819 in the Instituto Nacional da Propriedade Industrial (INPI), Brazil.

Supplementary Materials: The following are available online at http://www.mdpi.com/2076-393X/8/2/252/s1: Figure S1: Illustration of the Chimera's constructions. The multi-epitope vaccine sequence consisting of 24 MHC class I and II ligands. GPGPG sequence was used as linker to join the epitopes. H2A = Histone protein $2, \mathrm{LiP} 2 \mathrm{a}=$ Acid ribosomal protein $\mathrm{P} 2, \mathrm{LiP0}=$ Acid ribosomal protein $\mathrm{P} 0, \mathrm{LACK}=$ Leishmania homologue of activated $\mathrm{C}$ kinase, $\mathrm{CPC}=$ Cysteine peptidase $\mathrm{C}, \mathrm{CPA}=$ Cysteine peptidase $\mathrm{A}, \mathrm{CPB}=\mathrm{Cysteine}$ peptidase $\mathrm{B}$, PSA-50S = Surface antigenic protein, A2 = Amastigote protein A2, Figure S2: Evaluation of the expression of chimeric proteins A and B in the E. coli system. The expression was confirmed by SDS-PAGE as described in (a) and (b) for Chimeras A and B respectively. M1 = protein marker $1(120$ to $10 \mathrm{kDa}) ; 1=$ Bovine Serum Albumin $(2 \mu \mathrm{g}) ; 2=2 \mu \mathrm{g}$ of chimeric protein $\mathrm{A}(\sim 40 \mathrm{kDa})$ or B $(\sim 38 \mathrm{kDa})$. Also, the expression of the Chimera A (c) and Chimera B (d) was confirmed by Western Blot using anti-His antibody. M2 = protein marker $2(120$ to $22 \mathrm{kDa})$; $3=2 \mu \mathrm{g}$ of chimeric protein A (c) and B (d), Figure S3: Representative plot of the gating strategy for CFSE-labelled cells to evaluate the proliferation of splenocytes. The first step was to select the single cells, then the live cells using (FVS780). To characterize the T-lymphocytes anti-CD3, anti-CD4 and anti-CD8 were used followed by the proliferation analyses selecting the CFSElow-labelled cells.

Author Contributions: All the authors participated with suggestions and the development of this manuscript; R.C.F.D.B., J.M.d.O.C., T.L.V.D.P.O., L.E.S.R., F.A.S.M., and R.D.d.O.A.-S. performed all the experiments. R.C.F.D.B., J.C.R., and B.M.R. performed the analyses of data. R.C.F.D.B., J.C.R., J.M.O.C., T.L.V.D.P.O., L.E.S.R., F.A.S.M., B.M.R., D.d.M.R., J.C.R., A.B.R., and R.D.d.O.A.-S. participated in drafting the article and/or revising it critically for important intellectual content and created the figures and tables. R.C.-O., D.d.M.R., J.C.R., and A.B.R. participated in the study conception, critical revision of the article, and supervision. All authors have read and agreed to the published version of the manuscript.

Funding: This research received no external funding.

Acknowledgments: The authors acknowledge the Brazilian agencies $\mathrm{CNPq}$ (MCTI/CNPq/CT-BIOTEC-GENOPROT no. 560943/2010-5; MCTI/CNPq/CT-BIOTEC no. 27/2013, 301526/2015-0, 486618/2013-7, 310104/2018-1, and 435224/2018-2), FAPEMIG (APQ 03505-13 - PROGRAMA DE PESQUISA PARA O SUS - PPSUS MS/CNPq/FAPEMIG/SES, PRONEX APQ-01373-14, APQ-01661-13, PPM-00710-15, APQ-02638-17, APQ-02556-18, and APQ-00931-18), CAPES (this study was financed in part by the Coordenação de Aperfeiçoamento de Pessoal de Nível Superior - Brasil (CAPES) - Finance Code 001), UFOP, and FIOCRUZ for financial support. R.C.F.B., L.E.S.R., and D.M.R. are grateful for CAPES fellowships, and A.B.R., J.C.R., and B.M.R. are also grateful to CNPq for fellowships.

Conflicts of Interest: The authors declare that there is no conflict of interest.

\section{References}

1. Zutshi, S.; Kumar, S.; Chauhan, P.; Bansode, Y.; Nair, A.; Roy, S.; Sarkar, A.; Saha, B. Anti-Leishmanial Vaccines: Assumptions, Approaches, and Annulments. Vaccines (Basel) 2019, 7, 156. [CrossRef]

2. Sachdeva, R.; Banerjea, A.C.; Malla, N.; Dubey, M.L. Immunogenicity and efficacy of single antigen Gp63, polytope and polytopeHSP70 DNA vaccines against visceral leishmaniasis in experimental mouse model. PLoS ONE 2009, 4, e7880. [CrossRef] [PubMed] 
3. Seyed, N.; Taheri, T.; Vauchy, C.; Dosset, M.; Godet, Y.; Eslamifar, A.; Sharifi, I.; Adotevi, O.; Borg, C.; Rohrlich, P.S.; et al. Immunogenicity evaluation of a rationally designed polytope construct encoding HLA-A*0201 restricted epitopes derived from Leishmania major related proteins in HLA-A2/DR1 transgenic mice: Steps toward polytope vaccine. PLoS ONE 2014, 9, e108848. [CrossRef] [PubMed]

4. Das, S.; Freier, A.; Boussoffara, T.; Das, S.; Oswald, D.; Losch, F.O.; Selka, M.; Sacerdoti-Sierra, N.; Schonian, G.; Wiesmuller, K.H.; et al. Modular multiantigen T cell epitope-enriched DNA vaccine against human leishmaniasis. Sci. Transl. Med. 2014, 6, 234ra56. [CrossRef] [PubMed]

5. Seder, R.A.; Darrah, P.A.; Roederer, M. T-cell quality in memory and protection: Implications for vaccine design. Nat. Rev. Immunol. 2008, 8, 247-258. [CrossRef]

6. Darrah, P.A.; Patel, D.T.; De Luca, P.M.; Lindsay, R.W.; Davey, D.F.; Flynn, B.J.; Hoff, S.T.; Andersen, P.; Reed, S.G.; Morris, S.L.; et al. Multifunctional TH1 cells define a correlate of vaccine-mediated protection against Leishmania major. Nat. Med. 2007, 13, 843-850. [CrossRef]

7. De Groot, A.S. Immunomics: Discovering new targets for vaccines and therapeutics. Drug Discov. Today 2006, 11, 203-209. [CrossRef]

8. De Groot, A.S.; Berzofsky, J.A. From genome to vaccine-New immunoinformatics tools for vaccine design. Methods 2004, 34, 425-428. [CrossRef]

9. Brito, R.C.; Guimaraes, F.G.; Velloso, J.P.; Correa-Oliveira, R.; Ruiz, J.C.; Reis, A.B.; Resende, D.M. Immunoinformatics Features Linked to Leishmania Vaccine Development: Data Integration of Experimental and In Silico Studies. Int. J. Mol. Sci. 2017, 18, 371. [CrossRef]

10. Alves-Silva, M.V.; Nico, D.; Morrot, A.; Palatnik, M.; Palatnik-de-Sousa, C.B. A chimera containing CD4+ and CD8+ T-cell epitopes of the Leishmania donovani nucleoside hydrolase (NH36) optimizes cross-protection against Leishmania amazonesis infection. Front. Immunol. 2017, 8, 100. [CrossRef]

11. De Brito, R.C.F.; Cardoso, J.M.O.; Reis, L.E.S.; Mathias, F.A.S.; Aguiar-Soares, R.D.O.; Teixeira-Carvalho, A.; Roatt, B.M.; Correa-Oliveira, R.; Ruiz, J.C.; Resende, D.M.; et al. Synthetic Peptides Elicit Strong Cellular Immunity in Visceral Leishmaniasis Natural Reservoir and Contribute to Long-Lasting Polyfunctional T-Cells in BALB/c Mice. Vaccines (Basel) 2019, 7, 162. [CrossRef] [PubMed]

12. Larsen, M.V.; Lundegaard, C.; Lamberth, K.; Buus, S.; Lund, O.; Nielsen, M. Large-scale validation of methods for cytotoxic T-lymphocyte epitope prediction. BMC Bioinform. 2007, 8, 424. [CrossRef] [PubMed]

13. Buus, S.; Lauemoller, S.L.; Worning, P.; Kesmir, C.; Frimurer, T.; Corbet, S.; Fomsgaard, A.; Hilden, J.; Holm, A.; Brunak, S. Sensitive quantitative predictions of peptide-MHC binding by a 'Query by Committee' artificial neural network approach. Tissue Antigens 2003, 62, 378-384. [CrossRef] [PubMed]

14. Nielsen, M.; Lundegaard, C.; Lund, O. Prediction of MHC class II binding affinity using SMM-align, a novel stabilization matrix alignment method. BMC Bioinform. 2007, 8, 238. [CrossRef] [PubMed]

15. Xue, X.; Ding, F.; Zhang, Q.; Pan, X.; Qu, L.; Pan, W. Stability and potency of the Plasmodium falciparum MSP1-19/AMA-1(III) chimeric vaccine candidate with Montanide ISA720 adjuvant. Vaccine 2010, 28, 3152-3168. [CrossRef]

16. Real, F.; Vidal, R.O.; Carazzolle, M.F.; Mondego, J.M.; Costa, G.G.; Herai, R.H.; Wurtele, M.; de Carvalho, L.M.; Carmona e Ferreira, R.; Mortara, R.A.; et al. The genome sequence of Leishmania (Leishmania) amazonensis: Functional annotation and extended analysis of gene models. DNA Res. 2013, 20, 567-581. [CrossRef]

17. Khan, M.; Khan, S.; Ali, A.; Akbar, H.; Sayaf, A.M.; Khan, A.; Wei, D.Q. Immunoinformatics approaches to explore Helicobacter Pylori proteome (Virulence Factors) to design B and T cell multi-epitope subunit vaccine. Sci. Rep. 2019, 9, 13321. [CrossRef]

18. Kallberg, M.; Wang, H.; Wang, S.; Peng, J.; Wang, Z.; Lu, H.; Xu, J. Template-based protein structure modeling using the RaptorX web server. Nat. Protoc. 2012, 7, 1511-1522. [CrossRef]

19. Heo, L.; Park, H.; Seok, C. GalaxyRefine: Protein structure refinement driven by side-chain repacking. Nucleic Acids Res. 2013, 41, W384-W388. [CrossRef]

20. Wiederstein, M.; Sippl, M.J. ProSA-web: Interactive web service for the recognition of errors in three-dimensional structures of proteins. Nucleic Acids Res. 2007, 35, W407-W410. [CrossRef]

21. Lovell, S.C.; Davis, I.W.; Arendall, W.B., 3rd; de Bakker, P.I.; Word, J.M.; Prisant, M.G.; Richardson, J.S.; Richardson, D.C. Structure validation by Calpha geometry: Phi, psi and Cbeta deviation. Proteins 2003, 50, 437-450. [CrossRef] [PubMed]

22. Vajda, S.; Yueh, C.; Beglov, D.; Bohnuud, T.; Mottarella, S.E.; Xia, B.; Hall, D.R.; Kozakov, D. New additions to the ClusPro server motivated by CAPRI. Proteins 2017, 85, 435-444. [CrossRef] [PubMed] 
23. Berman, H.M.; Westbrook, J.; Feng, Z.; Gilliland, G.; Bhat, T.N.; Weissig, H.; Shindyalov, I.N.; Bourne, P.E. The Protein Data Bank. Nucleic Acids Res. 2000, 28, 235-242. [CrossRef] [PubMed]

24. PDB. Available online: http://www.rcsb.org/ (accessed on 11 November 2019).

25. Moreira, N.; Vitoriano-Souza, J.; Roatt, B.M.; Vieira, P.M.; Ker, H.G.; de Oliveira Cardoso, J.M.; Giunchetti, R.C.; Carneiro, C.M.; de Lana, M.; Reis, A.B. Parasite burden in hamsters infected with two different strains of leishmania (Leishmania) infantum: “Leishman Donovan units" versus real-time PCR. PLoS ONE 2012, 7, e47907. [CrossRef]

26. Reis, A.B.; Teixeira-Carvalho, A.; Vale, A.M.; Marques, M.J.; Giunchetti, R.C.; Mayrink, W.; Guerra, L.L.; Andrade, R.A.; Correa-Oliveira, R.; Martins-Filho, O.A. Isotype patterns of immunoglobulins: Hallmarks for clinical status and tissue parasite density in Brazilian dogs naturally infected by Leishmania (Leishmania) chagasi. Vet. Immunol. Immunopathol. 2006, 112, 102-116. [CrossRef]

27. Coler, R.N.; Goto, Y.; Bogatzki, L.; Raman, V.; Reed, S.G. Leish-111f, a recombinant polyprotein vaccine that protects against visceral Leishmaniasis by elicitation of CD4+ T cells. Infect. Immun. 2007, 75, 4648-4654. [CrossRef]

28. Dias, D.S.; Ribeiro, P.A.F.; Martins, V.T.; Lage, D.P.; Costa, L.E.; Chavez-Fumagalli, M.A.; Ramos, F.F.; Santos, T.T.O.; Ludolf, F.; Oliveira, J.S.; et al. Vaccination with a CD4(+) and CD8(+) T-cell epitopes-based recombinant chimeric protein derived from Leishmania infantum proteins confers protective immunity against visceral leishmaniasis. Transl. Res. 2018, 200, 18-34. [CrossRef]

29. Sanchez-Sampedro, L.; Gomez, C.E.; Mejias-Perez, E.; Sorzano, C.O.; Esteban, M. High quality long-term CD4+ and CD8+ effector memory populations stimulated by DNA-LACK/MVA-LACK regimen in Leishmania major BALB/c model of infection. PLoS ONE 2012, 7, e38859. [CrossRef]

30. Reis, L.E.S.; Brito, R.C.F.; Cardoso, J.M.O.; Mathias, F.A.S.; Aguiar Soares, R.D.O.; Carneiro, C.M.; de Abreu Vieira, P.M.; Ramos, G.S.; Frezard, F.J.G.; Roatt, B.M.; et al. Mixed Formulation of Conventional and Pegylated Meglumine Antimoniate-Containing Liposomes Reduces Inflammatory Process and Parasite Burden in Leishmania infantum-Infected BALB/c Mice. Antimicrob. Agents Chemother. 2017, 61, e00962-17. [CrossRef]

31. Vaure, C.; Liu, Y. A comparative review of toll-like receptor 4 expression and functionality in different animal species. Front. Immunol. 2014, 5, 316. [CrossRef]

32. Zandieh, M.; Kashi, T.; Taheri, T.; Zahedifard, F.; Taslimi, Y.; Doustdary, M.; Habibzadeh, S.; Eslamifar, A.; Shokri, F.; Rafati, S.; et al. Assessment of protection induced by DNA and live vaccine encoding Leishmania MHC class I restricted epitopes against L. major challenge in Balb/c mice model. Microb. Biochem. Technol. 2015, 7, 427-438. [CrossRef]

33. Soto, M.; Alonso, C.; Requena, J.M. The Leishmania infantum acidic ribosomal protein LiP2a induces a prominent humoral response in vivo and stimulates cell proliferation in vitro and interferon-gamma (IFN-gamma) production by murine splenocytes. Clin. Exp. Immunol. 2000, 122, 212-218. [CrossRef] [PubMed]

34. Rafati, S.; Nakhaee, A.; Taheri, T.; Taslimi, Y.; Darabi, H.; Eravani, D.; Sanos, S.; Kaye, P.; Taghikhani, M.; Jamshidi, S.; et al. Protective vaccination against experimental canine visceral leishmaniasis using a combination of DNA and protein immunization with cysteine proteinases type I and II of L. infantum. Vaccine 2005, 23, 3716-3725. [CrossRef] [PubMed]

35. Fernandes, A.P.; Costa, M.M.S.; Coelho, E.A.F.; Michalick, M.S.M.; de Freitas, E.; Melo, M.N.; Tafuri, W.L.; Resende, D.M.; Hermont, V.; Abrantes, C.D.; et al. Protective immunity against challenge with Leishmania (Leishmania) chagasi in beagle dogs vaccinated with recombinant A2 protein. Vaccine 2008, 26, 5888-5895. [CrossRef]

36. Khoshgoo, N.; Zahedifard, F.; Azizi, H.; Taslimi, Y.; Alonso, M.J.; Rafati, S. Cysteine proteinase type III is protective against Leishmania infantum infection in BALB/c mice and highly antigenic in visceral leishmaniasis individuals. Vaccine 2008, 26, 5822-5829. [CrossRef]

37. Ramos, I.; Alonso, A.; Marcen, J.M.; Peris, A.; Castillo, J.A.; Colmenares, M.; Larraga, V. Heterologous prime-boost vaccination with a non-replicative vaccinia recombinant vector expressing LACK confers protection against canine visceral leishmaniasis with a predominant Th1-specific immune response. Vaccine 2008, 26, 333-344. [CrossRef] 
38. Baharia, R.K.; Tandon, R.; Sahasrabuddhe, A.A.; Sundar, S.; Dube, A. Nucleosomal histone proteins of L. donovani: A combination of recombinant $\mathrm{H} 2 \mathrm{~A}, \mathrm{H} 2 \mathrm{~B}, \mathrm{H} 3$ and $\mathrm{H} 4$ proteins were highly immunogenic and offered optimum prophylactic efficacy against Leishmania challenge in hamsters. PLoS ONE 2014, 9, e97911. [CrossRef]

39. Oliva, G.; Nieto, J.; Foglia Manzillo, V.; Cappiello, S.; Fiorentino, E.; Di Muccio, T.; Scalone, A.; Moreno, J.; Chicharro, C.; Carrillo, E.; et al. A randomised, double-blind, controlled efficacy trial of the LiESP/QA-21 vaccine in naive dogs exposed to two leishmania infantum transmission seasons. PLoS Negl. Trop. Dis. 2014, 8, e3213. [CrossRef]

40. Pereira, L.; Abbehusen, M.; Teixeira, C.; Cunha, J.; Nascimento, I.P.; Fukutani, K.; dos-Santos, W.; Barral, A.; de Oliveira, C.I.; Barral-Netto, M.; et al. Vaccination with Leishmania infantum acidic ribosomal P0 but not with nucleosomal histones proteins controls Leishmania infantum infection in hamsters. PLoS Negl. Trop. Dis. 2015, 9, e0003490. [CrossRef]

41. Nezafat, N.; Eslami, M.; Negahdaripour, M.; Rahbar, M.R.; Ghasemi, Y. Designing an efficient multi-epitope oral vaccine against Helicobacter pylori using immunoinformatics and structural vaccinology approaches. Mol. Biosyst. 2017, 13, 699-713. [CrossRef]

42. Khatoon, N.; Pandey, R.K.; Prajapati, V.K. Exploring Leishmania secretory proteins to design B and T cell multi-epitope subunit vaccine using immunoinformatics approach. Sci. Rep. 2017, 7, 8285. [CrossRef] [PubMed]

43. Kumar Pandey, R.; Ojha, R.; Mishra, A.; Kumar Prajapati, V. Designing B- and T-cell multi-epitope based subunit vaccine using immunoinformatics approach to control Zika virus infection. J. Cell. Biochem. 2018, 119, 7631-7642. [CrossRef] [PubMed]

44. Pandey, R.K.; Bhatt, T.K.; Prajapati, V.K. Novel Immunoinformatics Approaches to Design Multi-epitope Subunit Vaccine for Malaria by Investigating Anopheles Salivary Protein. Sci. Rep. 2018, 8, 1125. [CrossRef] [PubMed]

45. Chauhan, V.; Rungta, T.; Goyal, K.; Singh, M.P. Designing a multi-epitope based vaccine to combat Kaposi Sarcoma utilizing immunoinformatics approach. Sci. Rep. 2019, 9, 2517. [CrossRef] [PubMed]

46. Nezafat, N.; Karimi, Z.; Eslami, M.; Mohkam, M.; Zandian, S.; Ghasemi, Y. Designing an efficient multi-epitope peptide vaccine against Vibrio cholerae via combined immunoinformatics and protein interaction based approaches. Comput. Biol. Chem. 2016, 62, 82-95. [CrossRef]

47. Apostolico, J.S.; Lunardelli, V.A.S.; Yamamoto, M.M.; Cunha-Neto, E.; Boscardin, S.B.; Rosa, D.S. Poly(I:C) Potentiates T Cell Immunity to a Dendritic Cell Targeted HIV-Multiepitope Vaccine. Front. Immunol. 2019, 10, 843. [CrossRef]

48. Selvapandiyan, A.; Dey, R.; Nylen, S.; Duncan, R.; Sacks, D.; Nakhasi, H.L. Intracellular replication-deficient Leishmania donovani induces long lasting protective immunity against visceral leishmaniasis. J. Immunol. 2009, 183, 1813-1820. [CrossRef]

49. Okwor, I.B.; Jia, P.; Mou, Z.; Onyilagha, C.; Uzonna, J.E. CD8+ T cells are preferentially activated during primary low dose leishmania major infection but are completely dispensable during secondary anti-Leishmania immunity. PLoS Negl. Trop. Dis. 2014, 8, e3300. [CrossRef]

50. Reed, S.G.; Coler, R.N.; Mondal, D.; Kamhawi, S.; Valenzuela, J.G. Leishmania vaccine development: Exploiting the host-vector-parasite interface. Expert Rev. Vaccines 2016, 15, 81-90. [CrossRef]

51. Passero, L.F.; Carvalho, A.K.; Bordon, M.L.; Bonfim-Melo, A.; Carvalho, K.; Kallas, E.G.; Santos, B.B.; Toyama, M.H.; Paes-Leme, A.; Corbett, C.E.; et al. Proteins of Leishmania (Viannia) shawi confer protection associated with Th1 immune response and memory generation. Parasites Vectors 2012, 5, 64. [CrossRef]

52. Dey, R.; Dagur, P.K.; Selvapandiyan, A.; McCoy, J.P.; Salotra, P.; Duncan, R.; Nakhasi, H.L. Live attenuated Leishmania donovani p27 gene knockout parasites are nonpathogenic and elicit long-term protective immunity in BALB/c mice. J. Immunol. 2013, 190, 2138-2149. [CrossRef] [PubMed]

53. Uzonna, J.E.; Spath, G.F.; Beverley, S.M.; Scott, P. Vaccination with phosphoglycan-deficient Leishmania major protects highly susceptible mice from virulent challenge without inducing a strong Th1 response. J. Immunol. 2004, 172, 3793-3797. [CrossRef] [PubMed]

54. Martins, V.T.; Lage, D.P.; Duarte, M.C.; Carvalho, A.M.; Costa, L.E.; Mendes, T.A.; Vale, D.L.; Menezes-Souza, D.; Roatt, B.M.; Tavares, C.A.; et al. A recombinant fusion protein displaying murine and human MHC class I- and II-specific epitopes protects against Leishmania amazonensis infection. Cell. Immunol. 2017, 313, 32-42. [CrossRef] 
55. Bogdan, C.; Schroppel, K.; Lohoff, M.; Rollinghoff, M.; Solbach, W. Immunization of susceptible hosts with a soluble antigen fraction from Leishmania major leads to aggravation of murine leishmaniasis mediated by CD4+ T cells. Eur. J. Immunol. 1990, 20, 2533-2540. [CrossRef] [PubMed]

56. Manna, L.; Reale, S.; Vitale, F.; Gravino, A.E. Evidence for a relationship between Leishmania load and clinical manifestations. Res. Vet. Sci. 2009, 87, 76-78. [CrossRef] [PubMed]

57. Blackwell, J.M. Genetic susceptibility to leishmanial infections: Studies in mice and man. Parasitology 1996, 112 (Suppl. S1), S67-S74. [CrossRef] [PubMed]

58. Banerjee, A.; Bhattacharya, P.; Dagur, P.K.; Karmakar, S.; Ismail, N.; Joshi, A.B.; Akue, A.D.; KuKuruga, M.; McCoy, J.P., Jr.; Dey, R.; et al. Live Attenuated Leishmania donovani Centrin Gene-Deleted Parasites Induce IL-23-Dependent IL-17-Protective Immune Response against Visceral Leishmaniasis in a Murine Model. J. Immunol. 2018, 200, 163-176. [CrossRef]

59. Rodrigues, A.; Claro, M.; Alexandre-Pires, G.; Santos-Mateus, D.; Martins, C.; Valerio-Bolas, A.; Rafael-Fernandes, M.; Pereira, M.A.; Pereira da Fonseca, I.; Tomas, A.M.; et al. Leishmania infantum antigens modulate memory cell subsets of liver resident T lymphocyte. Immunobiology 2017, 222, 409-422. [CrossRef]

60. Farber, D.L.; Yudanin, N.A.; Restifo, N.P. Human memory T cells: Generation, compartmentalization and homeostasis. Nat. Rev. Immunol. 2014, 14, 24-35. [CrossRef]

61. Sprent, J. T memory cells: Quality not quantity. Curr. Biol. 2002, 12, R174-R176. [CrossRef]

62. Loeuillet, C.; Banuls, A.L.; Hide, M. Study of Leishmania pathogenesis in mice: Experimental considerations. Parasites Vectors 2016, 9, 144. [CrossRef] [PubMed]

63. Martins, V.T.; Duarte, M.C.; Lage, D.P.; Costa, L.E.; Carvalho, A.M.; Mendes, T.A.; Roatt, B.M.; Menezes-Souza, D.; Soto, M.; Coelho, E.A. A recombinant chimeric protein composed of human and mice-specific CD4(+) and CD8(+) T-cell epitopes protects against visceral leishmaniasis. Parasite Immunol. 2017, 39, e12359. [CrossRef] [PubMed]

(C) 2020 by the authors. Licensee MDPI, Basel, Switzerland. This article is an open access article distributed under the terms and conditions of the Creative Commons Attribution (CC BY) license (http://creativecommons.org/licenses/by/4.0/). 